\section{Incidence of fractured implants}

I read with interest Deepak Khatri's letter about a fractured Nexplanon implant in the January 2015 issue of this Journal. ${ }^{1}$ I would like to inform readers of another implant fracture, similar to that described by Alyson Elliman in this Journal 2 years ago, and subsequent related correspondence.

A patient had an uneventful reinsertion, and attended 7 months later having noticed a 'dip' in the implant that had not been present post-insertion. There was no history of any trauma. The patient's bleeding pattern had been scanty and irregular, unchanged from her previous implant bleed pattern.

On examination the implant was easily palpable at both distal and proximal ends, with a noticeable 'dip' in the centre portion. Implant removal and reinsertion was agreed with the patient. The implant was removed without difficulty using a 'pop out' technique from the distal end. Figure 1 shows the 'teeth marks' made by a Gillies dissecting forceps on the distal end of the implant. On close inspection the implant was seen to be fractured in the mid-section, without separation of the two parts, resulting in the angulation that the patient had noticed.

I informed the drug company and filed a Medicines and Healthcare products Regulatory Agency (MHRA) Yellow Card report online. After several months I was contacted by the implant's manufacturer for further details of the clinical incident. I have had no further correspondence since then.

It would be interesting to receive clarification from the manufacturer about the incidence of reported fractured implants. Do other/all practitioners report these events to both the manufacturer and the MHRA, I wonder?

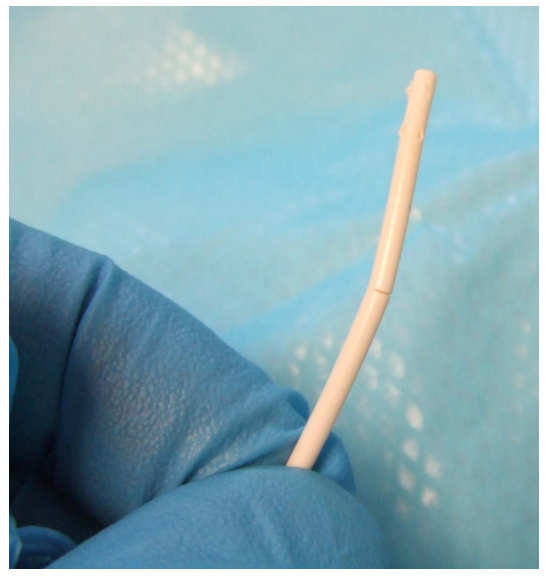

Figure 1 Photograph of the implant following removal, showing the fractured mid-section with clearly visible 'teeth marks' made by a Gillies dissecting forceps on the distal end. (Photograph kindly supplied by Dr Paul Davoren.)

Victoria Hartnell, DFSRH, MRCGP

General Practitioner and Level 2 Sexual Health Provider, Falmouth Health Centre, Falmouth, UK ; vicky.hartnell@nhs.net

\section{Competing interests None.}

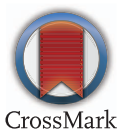

J Fam Plann Reprod Health Care 2015;41:157. doi:10.1136/jprhc-2015-101209

\section{REFERENCES}

1 Khatri D. Fractured Nexplanon ${ }^{\circledR}$ implant. J Fam Plann Reprod Health Care 2015;41:77.

2 Elliman A. Removal of a fractured Nexplanon ${ }^{\circledR}$. J Fam Plann Reprod Health Care 2013;39:66-67. 